\title{
Principal Statistical Analysis Plan Version
}

National Cancer Institute

\section{Source}

National Cancer Institute. Principal Statistical Analysis Plan Version. NCI Thesaurus. Code C162667.

A type of statistical analysis plan that is the main, comprehensive, pre-specified collection of analyses that support the Clinical Study Report (CSR) or other similar study report. 